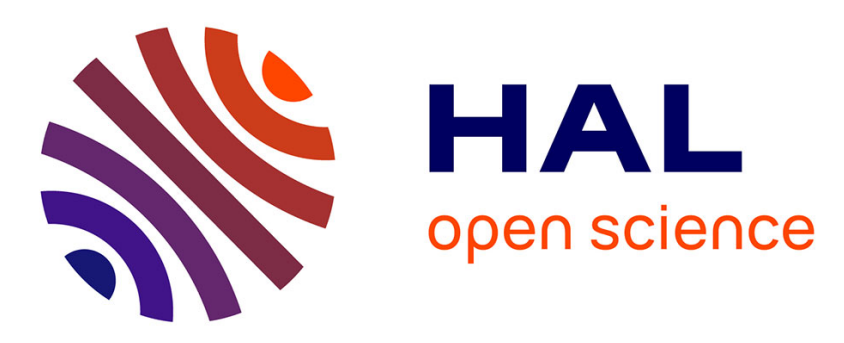

\title{
Storytelling on the Internet to develop weak-link networks. Two case studies Artistoria
}

Bernard Fallery, Carole Marti, Gerald Brunetto

\section{To cite this version:}

Bernard Fallery, Carole Marti, Gerald Brunetto. Storytelling on the Internet to develop weak-link networks. Two case studies Artistoria. ICEIS 9th International Conference on Enterprise Information Systems, Workshop HRIS, 2007, Funchal, Madeira, Portugal. pp.30-41. hal-00777898

\section{HAL Id: hal-00777898 \\ https://hal.science/hal-00777898}

Submitted on 23 Jan 2013

HAL is a multi-disciplinary open access archive for the deposit and dissemination of scientific research documents, whether they are published or not. The documents may come from teaching and research institutions in France or abroad, or from public or private research centers.
L'archive ouverte pluridisciplinaire HAL, est destinée au dépôt et à la diffusion de documents scientifiques de niveau recherche, publiés ou non, émanant des établissements d'enseignement et de recherche français ou étrangers, des laboratoires publics ou privés. 


\title{
Storytelling on the Internet
}

\section{to develop weak-link networks.}

\section{Two case studies "Artistoria"}

\author{
Bernard Fallery ${ }^{1}$, Carole Marti ${ }^{2}$, and Gerald Brunetto ${ }^{3}$ \\ ${ }^{1}$ CREGOR, University Montpellier 2, \\ 34000 Montpellier, France

\begin{abstract}
Is there an opportunity with Internet to build new weak-link networks for sharing knowledge and developing innovation? This article describes the research carried out in a French Regional Chamber of Trade and Crafts. Our work consisted of establishing two successive interactive portals collecting stories: about the experiences of craftsmen using ICT and about the experiences of collaborative spouses at work. Finally we propose a discussion of the weak links concept, in order to understand the opportunity with Internet to build new weak links networks for sharing knowledge and developing innovation.
\end{abstract}

\section{Introduction}

Relations between individuals of different social networks promote the ability to adapt to new situations. The capacity for innovation seems to increase as the ideas are spread via weak links: the study by Julien and al. (2002) [17] dealing with the innovative behaviour of small companies shows that the most innovative firms are those who use these weak links most often. Alternating strong links (a network where individuals have regular contact) and weak links (a network in which individuals have little contact) at the centre of a social body induces the effect of "structural gaps" required for new group dynamics and new strategies. So, what are the 
opportunities offered by the Internet today in the establishment of new weak-link networks for knowledge sharing?

Initially, we will develop the idea of "knowledge lifecycle" by presenting the different models proposed by researchers in three successive phases: creation, sharing and reuse. We will establish the characteristics necessary for a website dedicated to sharing narrated experiences in a weak links network.

Secondly we present Artistoria V.1 the tool that we have developed and implemented for craftsmen. Thirdly we present Artistoria V.2 the second tool that we are going to develop for collaborative spouses at work. Finally we propose a discussion of the weak links concept, in order to understand the opportunity with Internet to build new weak links networks for sharing knowledge and developing innovation.

\section{The idea of "knowledge lifecycle": creation, sharing and reuse.}

The analysis of the main knowledge management research within organisations can be used to highlight different interrelated activities: firstly, generation and storage, then the distribution and the application of experience (De Long and Fahey 2000 [5] Alavi and Leidner 2001 [1] Gold, Malhotra et al. 2001 [9]). To thus consider knowledge management as knowledge treatment process means that we can represent both the individual cognitive nature and the socio-cultural nature of organisational knowledge (Alavi and Leidner 2001 [1]). This process is thus based on a veritable knowledge lifecycle:

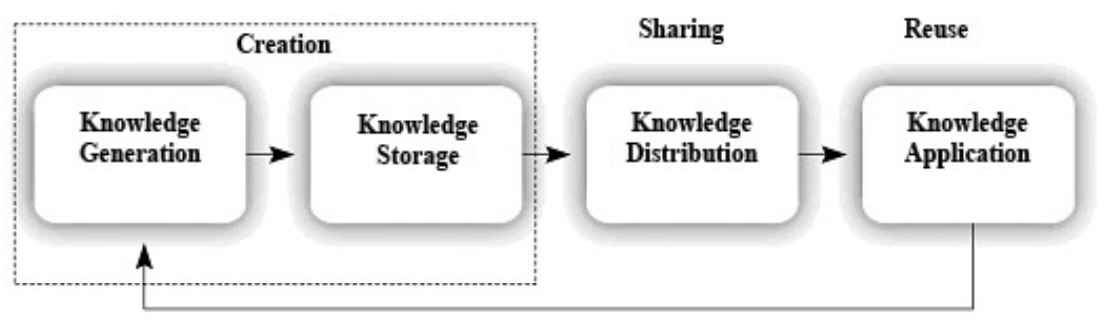

Fig. 1. Knowledge life cycle, according to Ruggle (1998) [23]

\subsection{Creation phase: generation and storage of knowledge}

The two initial stages of generation and storage are closely linked, given that they establish a body of knowledge to be managed. 
The knowledge generation process consists of establishing new content, replacing existing content, creating new knowledge from existing knowledge, etc. This stage is generally identified by different terms such as "acquisition, research, generation, creation, innovation, economic intelligence, capture, tracking, sourcing, etc ."

Then, in the context of a content management system, the challenge of the storage process is to allow fast and easy access to the stored knowledge: to choose the knowledge for storage, to adopt a suitable storage structure and support, etc. Storage thus consists of identification, collection and suitable presentation, whatever the context, of the knowledge acquired or created by an organisation or its members;

For our research we met with craftsmen and with collaborative spouses in craft and agricultural sectors. The stories were then transcribed and indexed according to the different dimensions resulting from our analysis.

\subsection{Distribution phase: Knowledge sharing}

Given the scattered nature of the organisational knowledge, organisations must be able to distribute it, if they wish to reuse previously stored content in different contexts (Zander and Kogut 1995 [25] O'Dell and Grayson 1998 [21]). Different authors agree on two stages in this distribution process. The first stage is externalisation (Hendriks 1999 [15]) of the knowledge, also referred to as the transmission process (Davenport and Prusak 1998 [4]) given that it consists of making the information available to others.

However the critical point becomes what we can call the dilemma of contextualisation: the fact that knowledge is contextualised gives it more significance (it will be richer because it is better rooted in the context of its acquisition) but as a result it will have more cognitive "stability" and will be thus more difficult to share in other contexts.

The problem of knowledge externalisation is followed by that of internalisation (Hendriks 1999 [15]), or the absorption process (Davenport and Prusak 1998 [4]). This is the second stage of sharing consisting of the "digestion" of the knowledge by other individuals. The individual who reads or listens to certain information will deal with it in a two-stage cognitive process: the de-contextualisation then the recontextualisation. We may first speak of a "read" step decontextualisation and "rewrite" step recontextualisation (Marti 2005 [20]) when the individual will reconstitute new knowledge in a new context.

Finally the problem of the degree of knowledge contextualisation appears to be crucial at this point: in most content management systems this must initially be identified (according to the needs of the future system users). However we suggest the use of a story structure creation tool which may be used for multiple and interactive searches, allowing a higher level of flexibility and personalisation: in a way, it is the user who could manage itself cognitive distance between "too much" or "too little" contextual information. 


\subsection{Re-use phase: the application of knowledge}

The final phase is that of reuse consisting of the application of knowledge (Fahey and Prusak 1998 [8]); Gold, Malhotra et al. 2001 [9]). However this is a concept not often considered in IS literature because it is difficult to observe. Effectively, this phase involves recalling the stored information (in a particular place, under a particular index or classification scheme, or the identification of the expert in the field, etc.) and the identification of user needs (Duffy 1999 [7]) so that they may really apply the knowledge. Some authors have, in fact, highlighted the fact that competitive advantage often results from the application of knowledge rather than its possession (Alavi and Leidner 2001 [1]), however this application process seems to be strongly dependent upon the absorption capacity (Cohen and Levinthal 1990 [3]) of the organisation members.

For Markus (2001) [19], the reuse of knowledge takes the form of four different activities. The first stage is the definition of the research question and is essential for the success of the reuse stage. The second stage is the search for and the localisation of the expert or expertise. The third stage is the selection of the expert or of the suitable consultancy, according to the results of the research. Finally, the fourth stage is the application of the knowledge in a recontextualisation process (given that the knowledge was most likely de-contextualised when it was captured or encoded). This final phase of reuse seems to be crucial for the organisation because it is this that finally determines the performance of all the knowledge management processes. In our research, even though we could not observe the final reuse phase, we will study closely their intentions to reuse the knowledge.

\section{ArtiStoria" V.1: a shared story database for craftsmen}

This research is thus being carried out in France in the context of a Regional Chamber of Trade and Crafts whose objective is to coordinate the action of the five departmental chambers and to guide the development of the craft sector. The task here consists of establishing an interactive portal collecting all the stories told by craftsmen regarding their use of ICTs, with the characteristics required of such a sharing tool: sourcing, indexing, consultation and reuse.

In a small company the work of the director is decisive, even exclusive, in the evaluation of potentials, however company directors do not often have the opportunity to meet "over a coffee" in order to share their experiences. Perhaps for the first time, the Internet may be used by small companies to enter far off markets and preserve existing contacts as well as creating new ones. 


\subsection{ArtiStoria V.1: a Web site for storytelling}

Our examination of the notion of knowledge lifecycle showed us the importance of the individual's management of the cognitive distance. We have thus developed the prototype "ArtiStoria V1" that takes all of these elements into account.

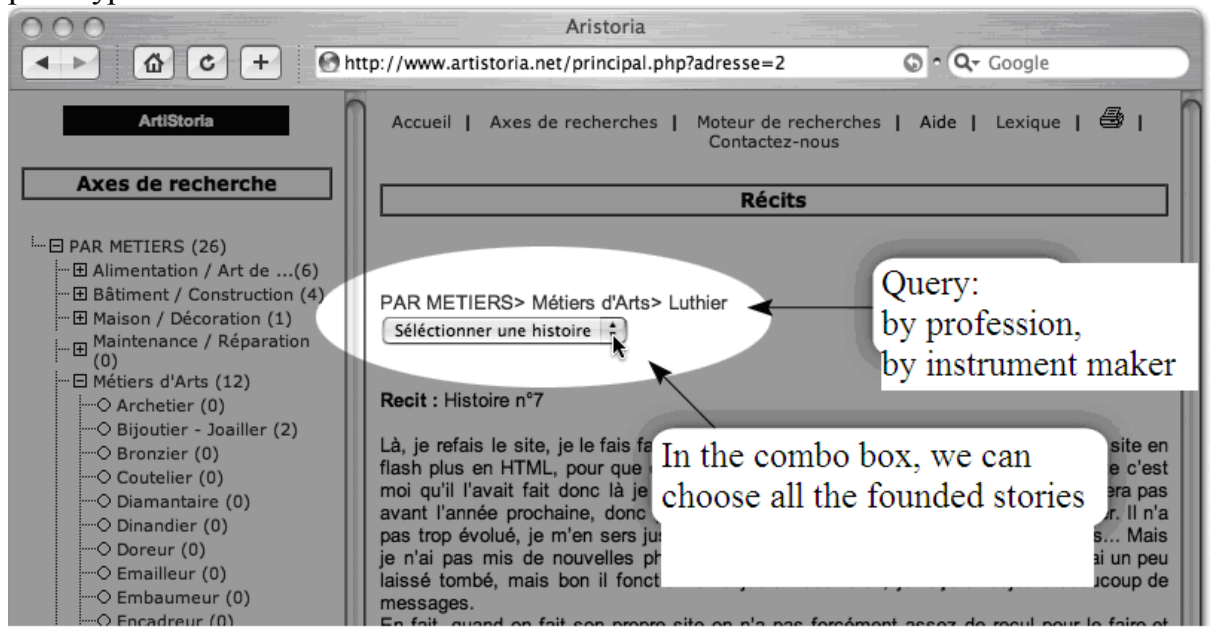

Fig 2. Example: Search for stories about instrument maker

In Artistoria, thanks to these different types of data access (using a full text search of stories, a full text search of the indexes, by themes, by complete stories, by story molecules, etc.), a craftsman will be able to search the database more freely: the cognitive distance may be managed according to the ability or difficulty they have managing the decontextualisation during the 'read' phase and the recontextualisation during the 'rewrite' phase.

\subsection{Using ArtiStoria V.1: for what type of sharing and for what reuse?}

The testing was carried out in three phases. The first phase is the "Before" Interview where we question the craftsman about their actual use and hopes for the Internet (for this first phase, eighty seven people participated and all of the interviews were recorded and transcribed). Then there is the "During" logbook phase when the craftsman is faced with the tool alone, they have to navigate and complete the logbook progressively, a questionnaire must also be completed so that each applicant is better characterised (finally forty-eight cases were complete and exploitable). Finally, there was the "After" Interview phase where we interviewed the craftsman according to their navigation on ArtiStoria.

Finally we showed that there are two types of cognitive distance: those who reuse within their sphere of activity and those who reuse outside their sphere of activity. Then we showed that according to the semantic distance applied by each individual 
to each particular piece of knowledge, they would use a smaller or larger part of the knowledge: "I adopt directly", "I adapt" and "I transform".

We can therefore cross-reference the different types of reuse with the different modes of cognitive distance. The scenarios are then defined according to the cognitive distance taken by individuals and the way in which they reuse the knowledge:

The cross-reference of these two dimensions results thus in six possible scenarios:

Table 1: The possible scenarios

\begin{tabular}{|c|c|c|c|}
\hline & $\begin{array}{c}\text { I adopt di- } \\
\text { rectly }\end{array}$ & $\begin{array}{c}\text { I } \\
\text { adapt }\end{array}$ & I transform \\
\hline Within & $(1)$ & $(3)$ & $(5)$ \\
\hline Outside & $(2)$ & $(4)$ & $(6)$ \\
\hline
\end{tabular}

The scenario "I ADOPT DIRECTLY, inside": 12 cases studied

The individuals in this category do not isolate the knowledge from its context, in other words they have difficulty decontextualising. Consequently, they "recontextualise" easily to translate the knowledge to their own professional context. The common factor that we found among all of these craftsmen is that they are only occasional users of Internet, either because they are new to Internet, because their profession does not really involve Internet use or simply because they have no desire to develop this use.

\section{The scenario "I ADAPT, inside and outside": 15 cases studied}

This scenario groups the craftsmen who have no problem handling cognitive distance. They are capable of reading the stories inside and outside of their context. Regarding reuse, they intend to ADAPT the knowledge. The important point of this scenario is that the craftsmen are capable of reading any type of story with sufficient distance to extract the interesting information. They decontextualise and recontextualise. They do not speak to us about specific examples but rather a general use which they find interesting and that they transpose to their own professional context. Most use the Internet on a daily basis for their profession, in particular for professionals in the areas of printing and graphics where the Internet is used daily to search for professional resources (typologies, logos, images). For professions such a baker, delicatessen, chocolate maker or instrument maker the Internet is an additional tool for their activity and used for the most part as client communication tool: they usually have a site. Lastly, for professions such as heating specialists, plumbers or bricklayers the use is different: craftsmen use the Internet to communicate with suppliers, to order goods or exchange photographs of sites.

\section{The scenario "I TRANSFORM, inside and outside": 10 of cases studied}

This category of "transformers" is quite different from the two previous categories. They read stories inside and outside of their professional context, however they TRANSFORM knowledge, more than simply adapting it they completely rephrase it. The craftsman will systematically decontextualise then recontextualise and imagine something new for their own activity. It is interesting to note that this is the only 
category in which certain craftsmen did not only search by profession but also used key words, links or other references. Regarding Internet use, all use Internet on a daily basis for their work. They are similar to those in the previous scenario however they seem to be more familiar and experienced in the area of computers.

\section{Artistoria V.2: Structuring the lifetime of collaborative spouses}

This second project is in progress regarding a second version of ArtiStoria. It is a European project EQUAL in collaboration with the network of Chambers of Trade and Crafts and the agricultural sector with the aim of providing a common base for all the collaborative spouses. The tool will be used to form an initial knowledge database that, using keywords, may be consulted on the Internet. This knowledge management tool may be used to benefit from experiences in order to facilitate location, preservation, development and updating. It will facilitate an inventory of best life practices: within the framework of a monitoring method to support thinking and actions to be taken and or the transfer of knowledge and best practices between collaborative spouses. One of the objectives for the international partnership will be to feed the database and thus constitute, over time, a European wide knowledge management tool.

\subsection{Data analysis for account structure}

In this case we collect 96 different stories directly from people in their homes and we used the Alceste, software which is based on syntactic analysis of repetition and cooccurrence (the simultaneous occurrence of two linguistic units).

The 96 stories are automatically divided into 1023 elementary units so that each ECU (Elementary Context Unit) contains a different number of analysed words. Finally Alceste retain 616 representative ECUs to be divided into classes for a descending hierarchical classification or DHC by successive division of the text: the first class analysed includes all of the retained context units, then, at each stage, all of the remaining classes are divided in two, maximising the Chi-squared test.

The following are typical ECUs:

ECU Khi2 Typical Elementary Context Units of Class 1:

$66427 \quad$ We tried to separate our work life and our family life, etc. our friends, our hobbies, even if they are few, but we still manage to have some recovery time.

24624 for example, on Wednesdays we did not work. We did not go to the office unless it was really urgent. It is both positive and negative. It is true that we think that we can do it later. At the same time, we must try all the same. For that reason I try to fix hours for myself.

Five classes were described according to the words used to define them, for example: 
Class 1: Home-Family (117 ECU classified out of 616, that is 19\%): to try, thing, available, house, organise, important, to separate, function, project, family, week, office, together, week-end, daily ...

Class 2: Timetable (103 ECU classified out of 616, that is $16 \%$ ): morning, to eat, evening, afternoon, obligation, educational, traffic, to leave, midday, school, washing, child, sister, meal, quarter...

Class 3: Business (138 ECU classified out of 616, that is 22\%): client, Internet, computer, supplier, to listen, account, to call, structure, schedule, place, message, feedback, to explain, satisfied, recent...

A hierarchical analysis by ascending classification (AHC) is used to define various sub-classes in each class. Here we will give only one example in Class 2 "Timetable" that may be broken down into: evening, obligations, meals, problems, homework support, weekends.

The contingency tables were then submitted to a factorial correspondence analysis (FCA) by cross-referencing the retained vocabulary with the ECU classes. Here the objective is to obtain a schematic spatial representation of inter-class relationships: - firstly, on the horizontal axis 1 (indicating $34 \%$ of the total dispersion) we see that "House-Family" (right hand side) is opposed to "Status" (left hand side) - on the vertical axis 2 (indicating $28 \%$ of the total dispersion) we note that "Timetable" and "Status" (above) are clearly opposed to "Business" and "Training".

\subsection{Development of the version Artistoria V.2}

Accounts and stories relate people to social events, procedures and organisations. For the past twenty years, the concept of accounts has been increasingly used in social science. Stories, in particular, are also becoming more popular both in the area of management science (Marti (2005)[20]), and in the sphere of knowledge management and information science.

We consider this coming together between management sciences and "story sciences" interesting given that the use of stories is a familiar human ability. Accounts have a key role in social sciences because they represent a great method of understanding a situation, and to order a collection of information: people think more in a "narrative" manner rather than an "argumentative" or "paradigmatic" manner. The narrative organisation of a personal experience is a particularly interesting way to convey understanding.

At the present stage of the process, we can offer a statistic method to divide the accounts into units (96 stories were used to structure 616 account units). We can now create "reconstructed" stories using these units and each one of these reconstructed stories will have the characteristics of a category. One of the characteristics of the Artistoria V.2 will be the exchange of comments on each story online using an annotation server. This work clearly involves several disciplines: language science (narratology), computer science (annotations, ontology, Semantic Web), information and communication sciences (cognition, uses, Internet media), and management science (appropriation, knowledge management, reuse, innovation). 


\section{Discussion: Internet, an opportunity for weak links networks?}

Granovetter (2000) [12] defines weak link networks as those where individuals have little interaction over time, low emotional intensity, little trust and few reciprocal services. The idea of an "interpersonal link" is at the heart of his analysis: "a link whose strength is a combination (probably linear) of time, emotional intensity, intimacy (mutual trust) and the reciprocal services that define it" (Granovetter 2000, p. 46-47) [12]. The absence of strong links between two groups even constitutes what Burt (1992) [2] called a "structural gap". The "bridge", that is the weak link between two independent groups, is extremely valuable since it generates informational variety in each group. The more structural gaps there are in a network, the higher the informational benefit of the network will be. By becoming a member of an association, an individual acquires a virtual social capital and potentially has access to all members of the community without necessarily being personally acquainted with each one.

In the case of craftsmen, the role of leader is decisive if not exclusive and it is thus extremely important for the craftsman to adapt the tools that will help them better play their role as interface: competition advantage may therefore originate not from the creativity of one individual but from the ability to build an innovative network of "weak-link" contacts (Julien, Andriambeloson et al. 2002) [17]. Unlike traditional strong-link networks (that could consist of, for example, a chartered accountant, a banker, suppliers, customers, a Chamber of trade, etc.) these weak-link networks are sociologically distanced from the leader (training courses, management clubs, professional trade shows, trainee welcome programmes, exhibitions, online training, senior sponsorships, etc.). Internet may thus multiply the capacities of companies provided that we know how to benefit from this: technological awareness, international links, new contacts, opportunity strategies, often commercial and incremental innovations, local production systems, etc. Consequently, our study shows that the use of stories and is a good knowledge sharing method and has clarified the ideas of cognitive distance and semantic density by identifying three types of reuse scenarios.

In the case of the project "Recognition and independence of collaborative spouses" the objective is to remove the obstacles for a concrete recognition of the spouses of entrepreneurs. This is to encourage the participation of women in economic life and employment, to promote the place of spouses in the company and in the representative professional authorities in order to guide each spouse in the organisation of their professional work so that each member of a couple may, under the best of conditions, develop a balance between family life and professional activity. Thus the Internet may be used to create weak links by research common to crafts and agriculture based on the inventory of needs in the form of "life stories". Our study shows that stories are still an excellent manner to share experiences, it defines the idea of indexing stories, highlights the need to create a comments annotation system and the need to make multimedia documents available. 


\section{References}

1. Alavi, M. and D. E. Leidner (2001). "Review : knowledge management and knowledge management systems : conceptual foundation and research issues." MIS Quarterly 25(1): 107-136.

2. Burt, S. R. (1995). "Le capital social, les trous structuraux et l'entrepreneur." Revue Française de Sociologie XXXVI(4): 599-628.

3. Cohen, W. M. and D. A. Levinthal (1990). "Absorptive capicity : a new perspective on learning and innovation." Administrative Science Quarterly 35(1): 128-152.

4. Davenport, T. H. and L. Prusak (1998). Working knowledge: how organizations manage what they know. Boston, Harvard Business School Press.

5. De Long, D. W. and L. Fahey (2000). "Diagnosing cultural barriers to knowledge management." The Academy of Management Executive 14(4): 113-127.

6. Dibiaggio, L. et M. Ferrary (2003). "Communautés de pratique et réseaux sociaux dans la dynamique de fonctionnement des clusters de hautes technologies." Revue d'économie industrielle(103): 111-130.

7. Duffy, D. (1999). "It takes an e-village." CIO Enterprise Magazine.

8. Fahey, L. and L. Prusak (1998). "The eleven deadliest sins of knowledge management." California Management Review 40(3): 265-275.

9. Gold, H. A., A. Malhotra, et al. (2001). "Knowledge management : an organizational capabilities perspective." Journal of Management Information Systems 18(1): 185-214.

10. Granovetter, M. (1973). "The strength of weak ties." American Journal of Sociology 78(6): $1360-1380$

11. Granovetter, M. (1985). "Economic action and social culture : the problem of embeddedness." American Journal of Sociology 78(6): 481-510.

12. Granovetter, M. (2000). Le marché autrement : les réseaux dans l'économie. Paris, Desclée de Brouwer.

13. Grant, R. M. (1996). "Prospering in dynamically-competitive environnements : organizational capability as knowledge integration." Organization Science 7(4): 375-387.

14. Hansen, M. T. (1999). "The search-transfer problem : the role of weak ties in sharing knowledge across organization subunits." Administrative Science Quarterly 44(1): 82-111.

15. Hendriks, P. (1999). "Why share knowledge? The influence of ICT on the motivation for knowledge sharing." Knowledge and Process Management 6(2): 91-100.

16. Jovanovic, B. (2001). "New technology and the small firm." Small Business Economics 16(1): 53-55.

17. Julien, P. A., E. Andriambeloson, et al. (2002). Réseaux, signaux faibles et innovation technologique dans les PME du secteur des équipements de transport terrestre. 6ème congrès international francophone de la PME, HEC Montréal.

18. Leonard-Barton, D. et D. K. Sinha (1993). "Developer-user interaction and user satisfaction in internal technology transfer." Academy of Management Journal 36(5): 1125-1139.

19. Markus, L. (2001). "Toward a theory of knowledge reuse: types of knowledge reuse situations and factors in reuse success." Journal of Management Information Systems 18(1): 57-91.

20. Marti, C. Fallery B. (2005). "Does the Knowledge management have a sense for the small companies? The storytelling between craftspeople". EMCIS, 8-10 Juin 2005, CAIRO

21. O'Dell, C. and J. C. Grayson (1998). "If only we knew what we know." California Management Review 40(3): 154-174.

22. Ruef, M. (2002). "Strong ties, weak ties and islands : structural and cultural predictors of organizational " Industrial and Corporate Change 11(3): 427-449. 